\title{
Test characteristics of neuroimaging in the emergency department evaluation of children for cerebrospinal fluid shunt malfunction
}

\author{
Ahmed Mater, MD; ${ }^{* * *}$ Manohar Shroff, MD; ${ }^{\dagger}$ Sami Al-Farsi, MD;§ James Drake, MD; \\ Ran D. Goldman, MD ${ }^{\mathbb{I} * *}$
}

See related article on page 174

\begin{abstract}
Objective: Cerebrospinal fluid (CSF) shunt malfunction is one of the most common life-threatening neurosurgical conditions. In the emergency department (ED), imaging techniques to identify shunt malfunction include the shunt series (SS) and CT scanning of the head. We sought to determine the test characteristics of the SS and CT scan for identifying children with shunt malfunction. Methods: We retrospectively reviewed the medical records of children with a CSF shunt who presented to our tertiary care pediatric emergency department and received an SS during a 2-year period from Jan. 1, 2001, to Dec. 31, 2002. A pediatric neuroradiologist reviewed all SS and CT scans. We defined shunt malfunction as present if the child underwent operative shunt revision.

Results: We identified 437 ED visits by 280 children. Forty-seven SS were read as abnormal. A CT scan was performed in $386(88.3 \%)$ cases and 80 were abnormal. Shunt malfunction was identified in $131(30.0 \%)$ children. Sensitivity, specificity, positive predictive value, negative predictive value, positive likelihood ratio and negative likelihood ratio of the SS for identifying cases of shunt malfunction were $30.0 \%, 95.8 \%, 72.3 \%, 75.1 \%, 7.1$ and 0.7 , respectively; for the CT scan, they were $61.0 \%, 82.7 \%, 64.5 \%, 80.5 \%, 3.5$ and 0.5 , respectively.

Conclusion: Neuroimaging has a low sensitivity for identifying shunt malfunction. Neurosurgical consultation should be sought if shunt malfunction is clinically suspected, despite normal imaging.

Keywords: shunt series, CT scan, hydrocephalus, emergency department

\section{RÉSUMÉ}

Objectif : Le dysfonctionnement du dispositif de dérivation appelé " shunt " du liquide céphalorachidien (LCR) est l'une des principales causes de complications neurochirurgicales mettant la vie du patient en danger. Dans les urgences, les techniques d'imagerie médicale utilisées pour repérer
\end{abstract}

From the *Division of Pediatric Emergency Medicine, Children's Hospital of Eastern Ontario, Ottawa, Ont., the tDepartment of Diagnostic Imaging and the ‡Division of Neurosurgery, The Hospital for Sick Children, University of Toronto, Toronto, Ont., the §Pediatric Research in Emergency Therapeutics (PRETx) Program, Division of Pediatric Emergency Medicine, Department of Pediatrics, The Hospital for Sick Children, University of Toronto, Toronto, Ont., and the IDepartment of Pediatrics, University of British Columbia, Vancouver, BC. At the time of writing, from the **Pediatric Research in Emergency Therapeutics (PRETx) Program, Division of Pediatric Emergency Medicine, Department of Pediatrics, The Hospital for Sick Children, University of Toronto, Toronto, Ont.

Received: Jan. 28, 2007; revisions received: July 26, 2007; accepted: Aug. 7, 2007

This article has been peer reviewed.

CJEM 2008;10(2):131-5 
un dysfonctionnement de shunt comprennent les radiographies multiples du shunt et la tomodensitométrie (TDM) cérébrale. Nous avons cherché à déterminer les caractéristiques des radiographies du shunt et de la TDM pour poser un diagnostic de dysfonctionnement d'un shunt chez l'enfant.

Méthode : Nous avons réalisé une étude rétrospective des dossiers médicaux d'enfants ayant un shunt du LCR, s'étant présentés au service des urgences pédiatriques de troisième ligne et ayant passé des radiographies au cours d'une période de 2 ans, du 1er janvier 2001 au 31 décembre 2002. Un neuroradiologue pédiatrique a évalué toutes les radiographies et les TDM. On détermine qu'il y a eu dysfonctionnement $d u$ shunt lorsque l'enfant a subi une reprise chirurgicale.

Résultats: Nous avons étudié les données relatives à 437 visites à l'urgence faites par 280 enfants. Quarante-sept radiographies étaient anormales. Une TDM a été réalisée dans 386 cas $(88,3 \%)$ et 80 se sont révélées anormales. On a posé un diagnostic de dysfonctionnement du shunt chez 131 enfants (30,0\%). La sensitivité, la spécificité, la valeur prédictive positive, la valeur prédictive négative, le rapport de vraisemblance positif et le rapport de vraisemblance négatif des radiographies pour repérer les cas de dysfonctionnement d'un shunt étaient respectivement $30,0 \%, 95,8 \%, 72,3 \%, 75,1 \%, 7,1$ et 0,7; pour la TDM, ils étaient respectivement $61,0 \%, 82,7 \%$, $64,5 \%, 80,5 \%, 3,5$ et 0,5 .

Conclusion : La sensitivité de la neuroimagerie est faible quand il s'agit de diagnostiquer un dysfonctionnement de shunt. Une consultation neurochirurgicale est nécessaire si l'on soupçonne cliniquement un tel dysfonctionnement, malgré les résultats normaux de l'imagerie.

\section{Introduction}

Cerebrospinal fluid (CSF) shunting is one of the most commonly performed neurosurgical operations. For individuals without normal CSF drainage, CSF shunting allows for the egress of fluid out of the head. Thus CSF shunting protects the patient from a life-threatening build up of intracranial pressure by diverting CSF to an alternative location (e.g., the peritoneal cavity) through a synthetic tube. Complications that can lead to life-threatening shunt malfunction and presentation to the emergency department (ED) include disconnection, calcification, migration of the shunt from its intended position and blockage..$^{1,2}$ Identifying patients with shunt malfunction and obtaining prompt neurosurgical consultation for shunt revision is an important task for emergency physicians.

Neuroimaging is typically obtained to help in identifying patients with shunt malfunction. ${ }^{3,4}$ Imaging usually includes a shunt series (SS) and a CT scan of the head. An SS is a set of plain radiographs of the entire course of the shunt tubing (e.g., skull, chest and abdominal radiographs). Possible causes of shunt malfunction, such as tube disconnection, fracture, calcification or migration of the tip from the intended end point may be identified on the SS. If shunt malfunction is present, an expected finding on CT scan of the head is absolute or relative ventriculomegaly. Currently, there is little evidence to support the use of this neuroimaging to identify children with shunt malfunction. ${ }^{5-7}$

We sought to determine the test characteristics of the SS and CT scan for identifying children with shunt malfunction.

\section{Methods}

Our facility is a tertiary care children's hospital that receives an average of 50000 emergency visits annually. It is a common practice in our ED to evaluate a child with suspected shunt blockage by first performing an SS. Then, if deemed necessary by the ED physician and the neurosurgical team, a CT scan is obtained. We retrospectively reviewed the medical records of all patients who presented to our pediatric ED with a shunting device and had an SS obtained between Jan. 1, 2001, and Dec. 31, 2002. The patient's hard copy or electronic charts or both were reviewed by 2 investigators (A.M. and S.A.). We defined a case as any visit to our ED during the study period during which a child underwent an SS. Therefore, owing to multiple visits during the study period by some children, a single child could contribute more than 1 case in our study. Patients were excluded if they had received an incomplete SS in the ED or if clinical data were missing from the chart. Patients were also excluded if they visited the ED within 2 weeks of a previous visit for the same chief complaint.

Collected data included demographic data, a history of the present illness and pertinent past medical history. Data regarding patient disposition, clinical outcome during hospital admission and surgical procedures were also included.

A pediatric neuroradiologist (M.S.) simultaneously reviewed all SS and CT scan films for each study subject and compared these studies with prior radiographic images, if available. The pediatric neuroradiologist was blinded to previous radiologic reports of the SS and CT and to the 
outcome of the patients. Findings on SS and CT scans were categorized. We grouped the SS findings into 4 categories: normal, discontinuity in the shunt tubing, a kink in the shunt tubing or some "other" abnormality. We grouped the CT findings into 6 categories: normal, hydrocephalus without previous $\mathrm{CT}$ for comparison, hydrocephalus that was unchanged from a prior comparison CT scan, increased hydrocephalus when compared with a prior CT scan, improved hydrocephalus compared with a prior CT scan or some "other" abnormality. Subsequently, we included hydrocephalus that was unchanged from a prior comparison CT scan and improved hydrocephalus compared with a prior CT scan in the "normal" category.

Our main outcome measure was the presence of shunt malfunction. If the neurosurgeon performed a shunt revision, we defined this as shunt malfunction. The neurosurgeons were not blinded to the findings on SS and CT scan when making their decision about performing a shunt revision.

Data were entered into Microsoft Excel 2003 (Microsoft Corporation, Redmond, Washington). SPSS for windows (version 13.0, SPSS, Inc. Chicago, Illinois) was used for data analysis. Sensitivity, specificity, positive and negative predictive values and likelihood ratios were calculated. Our study was approved by the Research Ethics Board at the Hospital for Sick Children in Toronto, Ontario.

\begin{tabular}{lcc}
$\begin{array}{l}\text { Table 1. Study subject enrolment by } \\
\text { number of visits }\end{array}$ \\
$\begin{array}{lcc}\text { No. of visits } \\
\text { per child }\end{array}$ & $\begin{array}{c}\text { No. of } \\
\text { children }\end{array}$ & $\begin{array}{c}\text { Total no. } \\
\text { of visits }\end{array}$ \\
\hline 1 & 189 & 189 \\
2 & 56 & 112 \\
3 & 20 & 60 \\
4 & 5 & 20 \\
5 & 6 & 30 \\
6 & 2 & 12 \\
7 & 2 & 14 \\
\hline Total & 280 & 437 \\
\hline
\end{tabular}

Table 2. Shunt malfunction by results of the shunt series

\begin{tabular}{lcc}
$\begin{array}{l}\text { Shunt series results; } \\
n=437\end{array}$ & $\begin{array}{c}\text { Shunt } \\
\text { malfunction }\end{array}$ & $\begin{array}{c}\text { No shunt } \\
\text { malfunction }\end{array}$ \\
\hline Normal & 97 & 293 \\
Discontinuity of the tubing & 30 & 3 \\
Kink in the tubing & 4 & 6 \\
Other abnormalities* & 0 & 4 \\
\hline Total & 131 & 306 \\
\hline *Other abnormalities included migration of the distal end of the tubing into \\
the scrotum (1 case), migration of the distal end of the tubing into the \\
sigmoid colon (1 case) and inconclusive results (2 cases).
\end{tabular}

\section{Results}

We identified 458 instances in which an SS was obtained during the study period. Of these, 11 were excluded because the medical record or images were incomplete or unavailable, 9 because the child had returned within 2 weeks of a previous visit for the same chief complaint and 1 case was excluded because the child was transferred from another hospital after neuroimaging had been obtained. Therefore, our main study group consisted of the remaining 437 visits. A total of 280 children were responsible for these 437 visits, and the number of visits by a single child during the study period ranged from 1 to 7 (Table 1). The majority of children enrolled in our study $(186,66.4 \%)$ visited the ED once during the study period. Of the 280 children in our study, 123 (43.9\%) were girls. Their mean age at presentation to the ED was 8.4 years (range $1.8 \mathrm{mo}$ to $18.8 \mathrm{yr}$ ). The etiology for hydrocephalus was congenital in $75(26.8 \%)$ children, myelomeningocele in 68 (24.3\%), neonatal intraventricular hemorrhage in 53 (18.9\%), brain tumours in $26(9.3 \%)$, meningitis in $13(4.6 \%)$, trauma in 9 (3.2\%) and other etiologies in $36(12.9 \%)$.

At least 3 different types of shunts were identified in our study population. Ventriculoperitoneal shunts were seen in 420 cases $(96.1 \%)$, ventriculopleural shunts in $6(1.1 \%)$ and cistoperitoneal shunts in $5(1.1 \%)$. Six cases $(1.1 \%)$ had more than 1 type of shunt.

Of our 437 cases, one-half $(219,50.1 \%)$ were discharged home from the ED and the remainder were admitted to the hospital. Shunt malfunction was diagnosed in $131(30.0 \%)$ cases.

Forty-seven (10.8\%) SS were abnormal (Table 2). A CT scan of the head was performed in $386(88.3 \%)$ cases. Of those children who underwent CT scanning, 41 (10.6\%)

Table 3. Shunt malfunction by results of head CT scanning

\begin{tabular}{|c|c|c|}
\hline Head CT scan results; $n=386$ & $\begin{array}{l}\text { Shunt } \\
\text { malfunction }\end{array}$ & $\begin{array}{c}\text { No shunt } \\
\text { malfunction }\end{array}$ \\
\hline Normal* & 51 & 211 \\
\hline $\begin{array}{l}\text { Increased hydrocephalus } \\
\text { compared with prior head } \\
\text { CT scans }\end{array}$ & 61 & 30 \\
\hline $\begin{array}{l}\text { Hydrocephalus with no prior } \\
\text { CT scan available for } \\
\text { comparison }\end{array}$ & 18 & 11 \\
\hline Other abnormalitiest & 1 & 3 \\
\hline \multicolumn{3}{|c|}{$\begin{array}{l}\text { * Includes cases in which the head CT demonstrated ventriculomegaly that was } \\
\text { unchanged when compared with prior head CT scans ( } 27 \text { of which had shunt } \\
\text { malfunction and } 105 \text { of which did not) and cases in which the head CT } \\
\text { demonstrated improved ventriculomegaly compared with prior head CT scans (14 } \\
\text { of which had shunt malfunction and } 55 \text { of which did not). } \\
\text { tOther abnormalities included enlarged right ventricle accompanied by a } \\
\text { decrease in the size of a cystic collection ( } 1 \text { case), subdural fluid collection (1 } \\
\text { case), schizoencephaly ( } 1 \text { case) and Chiari malformation type } 2 \text { ( } 1 \text { case). }\end{array}$} \\
\hline
\end{tabular}


underwent shunt revision despite having hydrocephalus that was either unchanged or improved compared with prior studies (Table 3).

Nine cases had abnormal findings on SS but not on the CT scan. Of these, 6 showed a kink in the shunt, 2 showed that the tubing had migrated into the scrotum and 1 revealed a disconnection in the shunt tubing. This child also had an abscess at the shunt site. Of these 9 cases, only this child had shunt malfunction.

The test characteristics for neuroimaging were calculated. Sensitivity, specificity, positive predictive value, negative predictive value, positive likelihood ratio and negative likelihood ratio of the SS for identifying cases of shunt malfunction were $30.0 \%, 95.8 \%, 72.3 \%, 75.1 \%, 7.1$ and 0.7 , respectively; for the CT scan they were $61.0 \%$, $82.7 \%, 64.5 \%, 80.5 \%, 3.5$ and 0.5 , respectively.

\section{Discussion}

The traditional imaging studies used to assist in diagnosing shunt malfunction are insensitive and have relatively poor test characteristics. Our results support those of prior studies with regard to both the SS and head CT scanning. Out of $67 \mathrm{SS}$ in 1 study, ${ }^{8}$ none were found to be abnormal, while one-third of the children had shunt malfunction. Another study found that SS had a sensitivity of $20 \%$ and a negative predictive value of $22 \%$. In this study, the yield of routine shunt series in detecting unsuspected abnormalities was low $(0.8 \%, 95 \%$ confidence interval $0.1 \%-3.0 \%){ }^{9}$

With regard to head CT scanning, it is intuitively appealing to think that shunt malfunction should lead to absolute or relative ventriculomegaly in nearly all cases. As intuitive as this concept is, it is wrong. Normal CT scans, those demonstrating stable ventriculomegaly and even those with decreased ventricular size compared with prior CT scans may be seen in children experiencing shunt malfunction. ${ }^{10-13}$ In one report of 100 children who had shunt malfunction, approximately $11 \%$ of the shunt failures had brain imaging studies (CT and magentic resonance imaging scans) showing small ventricles. ${ }^{14}$ Among 84 patients in another series, the false negative rate was $4 \%$ (small ventricles with a nonfunctioning shunt) and the false positive rate was $13 \%$ (large ventricles with a functioning shunt). ${ }^{15}$ Estimates of sensitivity of the CT scan reported in previous studies have ranged from $64 \%$ to $92 \% .^{9,14-16}$ These findings are similar to ours.

\section{Limitations}

Limitations of our study include its retrospective methodol- ogy, which potentially limits the generalizability of our results. We did not perform interrater reliability testing to assess the reproducibility of our findings. Also, the SS and CT scans were reviewed by a pediatric neuroradiologist. This may be different from actual practice. During the clinical care of our study subjects, a general radiologist typically provided the interpretations that impacted patient care. These readings may differ somewhat from those of a pediatric neuroradiologist. Our subject list was generated through the radiology database and it is possible that some children with shunt malfunctions came to the ED during the study period and did not have a shunt series performed. Our main study group included several visits by individual children. If there were some unique features to the children who had multiple visits during the study period, this may overrepresent these features in our results. This could adversely affect the generalizability of our results. In addition, the neurosurgeons were not blinded to the results of the neuroimaging. Since we defined shunt malfunction as the decision by the neurosurgeon to perform a shunt revision, we are at risk for introducing incorporation bias. However, incorporation bias would lead to an overestimation of the sensitivity of the SS and CT scanning. We demonstrated relatively poor sensitivity of the SS and head $\mathrm{CT}$ in detecting shunt malfunction. It is conceivable that owing to incorporation bias we have overestimated the sensitivity and that the true sensitivity is even worse than found in our study.

\section{Conclusion}

Our findings show that diagnostic neuroimaging has a low sensitivity for shunt malfunction. Neurosurgical consultation should be sought if shunt malfunction is clinically suspected, despite normal neuroimaging.

Competing interests: None declared.

\section{References}

1. Casey AT, Kimmings EJ, Kleinlugtebeld AD, et al. The longterm outlook for hydrocephalus in childhood: a ten-year cohort study of 155 patients. Pediatr Neurosurg 1997;27:63-70.

2. Di Rocco C, Marchese E, Velardi F. A survey of the first complication of newly implanted CSF shunt devices for the treatment of nontumoral hydrocephalus: cooperative survey of the 1991-1992 Education Committee of the ISPN. Childs Nerv Syst 1994;10:321-7.

3. Madikians A, Conway EE. Cerebrospinal fluid shunt problems in pediatric patients. Pediatr Ann 1997;26:613-20. 
4. Madsen MA. Emergency department management of ventriculoperitoneal cerebrospinal fluid shunts. Ann Emerg Med 1986; 15:1330-43.

5. Storrow AB. Intracranial shunt assessment. In: Roberts JR, Hedges JR, editors. Clinical procedures in emergency medicine. 3rd ed. Philadelphia (PA): Saunders Company; 1998. p. 1042-51.

6. Goeser CD, McLeary MS, Young LW. Diagnostic imaging of ventriculoperitoneal shunt malfunctions and complications. Radiographics 1998;18:635-51.

7. Rothrock SG, Green SM, Harding M, et al. Plain abdominal radiography in the detection of acute medical and surgical disease in children: a retrospective analysis. Pediatr Emerg Care 1991;7: 281-5.

8. Gilbreath PL, Mulligan ME, Sileo DR. Utilization and cost effectiveness review of shunt series to rule out ventriculoperitoneal shunt malfunction. Emerg Radiol 1999;6:345-9.

9. Zorc JJ, Krugman SD, Ogborn J, et al. Radiographic evaluation for suspected cerebrospinal fluid shunt obstruction. Pediatr Emerg Care 2002;18:337-40.

10. Amacher AL, Spence JD. Spectrum of benign intracranial hypertension in children and adolescents. Childs Nerv Syst 1985;1:81-6.

11. Borgesen SE, Gjerris F. Relationships between intracranial pressure, ventricular size, and resistance to CSF outflow. J Neurosurg 1987;67:535-9.

12. Fried A, Shapiro K. Subtle deterioration in shunted childhood hydrocephalus. A biomechanical and clinical profile. J Neurosurg 1986;65:211-6.

13. Engel M, Carmel PW, Chutorian AM. Increased intraventricular pressure without ventriculomegaly in children with shunts: "normal volume" hydrocephalus. Neurosurgery 1979;5:549-52.

14. Iskandar BJ, McLaughlin C, Mapstone TB, et al. Pitfalls in the diagnosis of ventricular shunt dysfunction: radiology reports and ventricular size. Pediatrics 1998;101:1031-6.

15. Murtagh FR, Quencer RM, Poole CA. Cerebrospinal fluid shunt function and hydrocephalus in the pediatric age group: a radiographic/clinical correlation. Radiology 1979;132:385-8.

16. Watkins L, Hayward R, Andar U, et al. The diagnosis of blocked cerebrospinal fluid shunts: a prospective study of referral to a paediatric neurosurgical unit. Childs Nerv Syst 1994;10:87-90.

Correspondence to: Dr. Ran D. Goldman, Division Head and Medical Director, Division of Pediatric Emergency Medicine, BC Children's Hospital, Associate Professor, Department of Pediatrics, University of British Columbia, Senior Associate Clinician Scientist, Child \& Family Research Institute (CFRI), Rm K4-226, Ambulatory Care Building, 4480 Oak St., Vancouver BC V6H 3V4; rgoldman@cw.bc.ca

\section{Erratum}

In the November 2007 issue of CJEM, Clinton T. Forsythe's ${ }^{1}$ surname was misspelled on the cover and table of contents pages. We apologize for this error and any inconvenience it may have caused.

\section{Reference}

1. Forsythe CT, Ernst ME. Do fluoroquinolones commonly cause arthropathy in children? CJEM 2007;9(6):459-62. 